\title{
Mathematical modeling of longitudinal dynamic pressure distribution on planing hulls
}

\author{
Sasan Tavakoli, Parviz Ghadimi", Abbas Dashtimanesh, Seyed Reza Djeddi \\ Department of Marine Technology, Amirkabir University of Technology \\ *Corresponding author E-mail:pghadimi@aut.ac.ir
}

\begin{abstract}
In the present paper, a mathematical model is used in order to predict the longitudinal distribution of dynamic pressure on planing hulls. The present model is based on the empirical equations resulted from multitude of experiments that have been carried out over the years on planing boats. These empirical equations are able to predict a longitudinal section of the pressure distribution. The obtained pressure field is then used to evaluate the dynamic pressure behind the stagnation line. A computer code is developed for the modeling purposes and the obtained results are validated against experimental data. In this regard, the effects of the trim angle, dead-rise angle and the wetted length on the longitudinal distribution of the dynamic pressure for the planing hulls are studied.
\end{abstract}

Keywords: Planing Hulls, Empirical Equations, Longitudinal Pressure Distribution, Mathematical Modeling, Hydrodynamics.

\section{Introduction}

Dynamic pressure acting on the bottom of a planing boat plays a significant role in the generation of lift force. Evaluation of this pressure field for planing hulls helps to recognize the dynamic behavior of the boat in a way that makes it possible to predict the distribution of forces on the body which leads to a successful study of its dynamic motions. On the other hand, the pressure field on the bottom of the hull can also be used in structural analyses.

This dynamic pressure field can be measured using experimental, analytical, CFD and empirical methods. As one of the pioneering studies, Wagner [1] introduced a relation based on the potential flow theory for the evaluation of the pressure distribution in the case of wedge water entry. As a result, using the measured pressure and the strip theory, it is possible to evaluate the dynamic pressure distribution over the bottom of a boat.

In another attempt, Sottorf [2] measured the pressure distribution over the prismatic planing hulls using experimental methods. Also, Smiley [3] carried out experiments for the calculation of the pressure distribution on planing hulls. He then introduced an empirical equation for prediction of the maximum pressure value acting on this type of hull. In another experimental work, Kapryan and Boyd [4] studied the effects of the trim angle, dead-rise angle and wetted length.

Based on the results obtained from experimental studies, Savitsky [5] presented a mathematical model for the prismatic planing hulls. This model is able to calculate hydrodynamic and hydrostatic forces acting on the planing hull. His mathematical model was among the first models introduced for the analysis of the planing boats. In a similar approach, Allen and Jones [6] used the equations of Smiley [3] in order to present a designing procedure for planing boats.

Subsequently, analytical methods were introduced and developed and Payne [7] calculated dynamic force and dynamic pressure distribution over a planing plate. Calculation of the flow field in the case of wedge water entry and the application of strip theory to the analysis of the planing hulls have been presented by many authors [8, 9 and 10]. Having the pressure field in vicinity of the planing hull, it is possible to evaluate the pressure at any given point over the planing body. In the recent years, Morabito [13] modified the equations of Smiley [3] in order to present semi-empirical equations for the calculation of maximum pressure and pressure distribution over the planing hulls.

Among all the developed techniques, empirical methods are proved to be simple and low cost approaches for the analysis of the planing boats. In the framework of these methods, it is possible to obtain favorable results by altering various parameters.

The goal of the present study is to use the semi-empirical equations of Morabito [13] in order to develop a mathematical model for evaluation of the longitudinal dynamic pressure distribution on planing hulls which will then be used to investigate the effects of different parameters on this pressure distribution. 


\section{Mathematical model}

It is stated by Pierson and Leshnover [12] that when the streamlines collide with a planing plane, the flow will be divided into two parts and the separation occurs over a line. This line extends on both sides of the longitudinal symmetry line and is called the stagnation line (as shown in Fig.1). Considering this stagnation line, the bottom of the planing hull is then consists of two areas:

1. Pressure Area; the area behind the stagnation line

2. Whisker Spray Area; the area in front of the stagnation line

The angle $\alpha$ between the stagnation line and the symmetry line is calculated using equation (1) as proposed by Savitsky [5]:

$\alpha=\tan ^{-1} \frac{\pi}{2} \frac{\tan \tau}{\tan \beta}$

in which $\tau$ and $\beta$ are the trim and dead-rise angles, respectively.

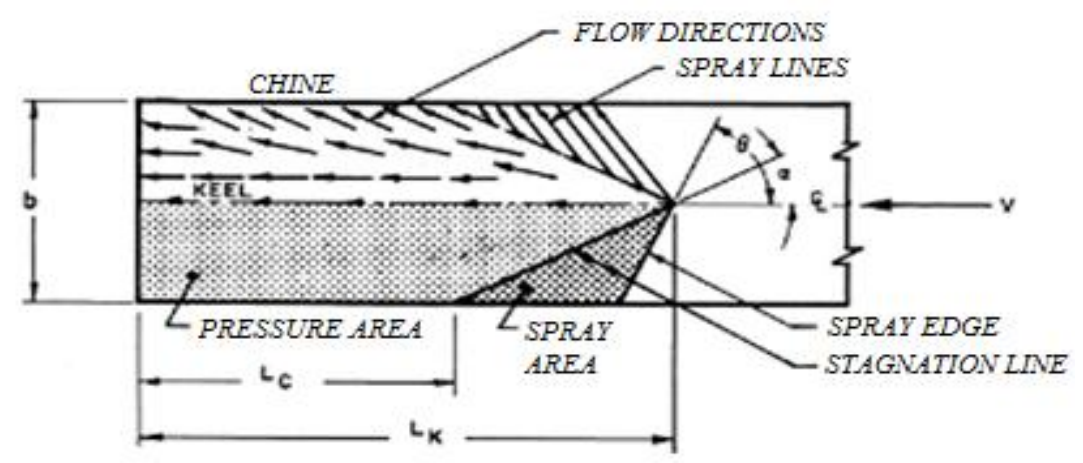

Fig.1: Bottom view of the planing plane parallel to keel [11].

Three-dimensional dynamic pressure distribution over a planing plane is depicted in Fig.2. It is obvious that pressure at the stagnation line is far greater than pressure at other parts of the plane. The complexity of the problem makes it almost impossible to apply direct methods for calculation of the pressure distribution and therefore the pressure is calculated in length-wise and breadth-wise directions separately and it is then extended to a 3-dimensional distribution over the plane.

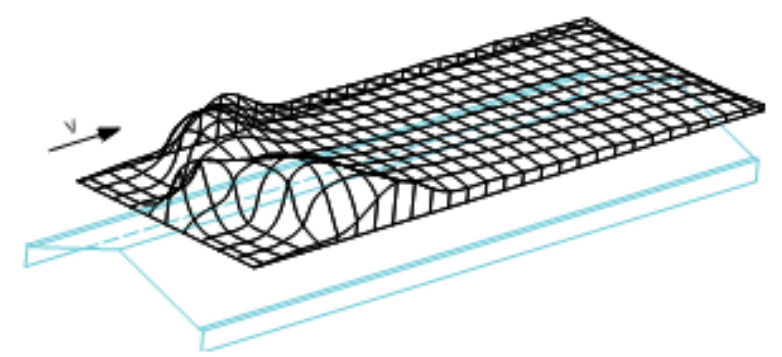

Fig.2: Three dimensional distribution of the pressure over the bottom of a planing hull.

The longitudinal distribution of the dynamic pressure over a planing plane exhibits a maximum at the stagnation point. After this peak, the pressure falls with a sharp steep and reaches the atmospheric pressure at each end of the plane. This phenomenon is presented in Fig.3.

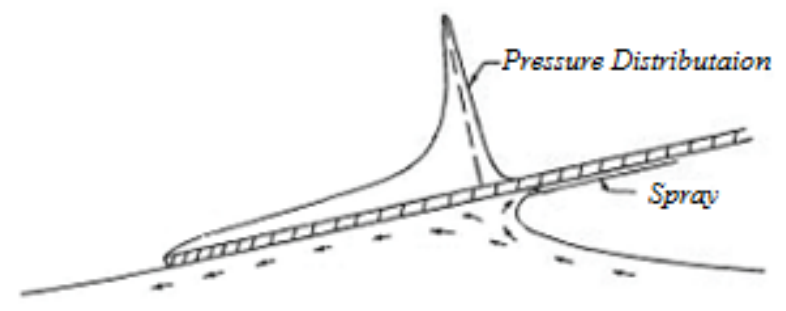

Fig.3: Longitudinal distribution of the dynamic pressure over a semi-infinite planing plane [14]. 


\subsection{Longitudinal distribution of pressure over the longitudinal symmetry line}

Equation (2) introduced by Morabito [13], is used to calculate the maximum pressure for the case of a planing hull as in

$\frac{P_{M A X}}{q}=\sin ^{2} \alpha$

where $P_{\max }$ is the maximum pressure at stagnation line, at the intersection of the keel and waterline, while $q$ is calculated as follows:

$q=\frac{1}{2} \rho V^{2}$

The pressure behind the stagnation line falls from this value and vanishes at the transom. Smiley [3] introduced the equation (4) for the pressure reduction behind the stagnation line and along the symmetry line.

$\frac{P_{L}}{q}=0.006 \frac{\tau^{\frac{1}{3}}}{X^{\frac{2}{3}}}$

Here, $P_{L}$ is the pressure behind the stagnation line and $X$ is the dimensionless distance from the stagnation line which is calculated using Equation (5). $X$ is given by the equation

$X=\frac{x}{b}$

where $b$ is the breadth. Morabito [13] modified equation (4) in order to evaluate the dynamic pressure reduction over a planing hull and introduced

$\frac{P}{q}=\frac{C X^{1 / 3}}{(X+K)}$

in which, $C$ and $K$ are constants that can be evaluated using simple mathematical and differential equations as follows [11]:

$C=0.006 \tau^{\frac{1}{3}}$

$K=\frac{C^{1.5}}{2.588\left(\frac{P_{M A X}}{q}\right)^{1.5}}$

Pressure distribution over the longitudinal symmetry line can be measured using equation (6), but the result would not be accurate for the pressure values at the transom.

\subsection{Effect of the transom stern}

Morabito [13] took into account the effect of the transom stern on the longitudinal distribution by introducing a coefficient such that with the multiplication of this coefficient and the longitudinal pressure distribution, the transom stern effect would be simulated. This will cause a major reduction of pressure starting from a half-breadth distance from the transom stern until the pressure vanishes at the transom. This coefficient is calculated using equation

$P_{T}=\frac{\left(\lambda_{y}-X\right)^{1.4}}{\left(\lambda_{y}-X\right)^{1.4}+0.05}$

in which $\lambda_{y}$ is the dimensionless distance between the transom stern and the stagnation line at each longitudinal section. This parameter is derived using the equation (10) as follows: 
$\lambda_{y}=\lambda-\frac{(Y-0.25)}{\tan \alpha}$

where $Y$ is the dimensionless transverse distance from the longitudinal symmetry line as in

$Y=\frac{y}{b}$

\subsection{Longitudinal pressure distribution over other longitudinal sections}

The equations presented so far offer the longitudinal pressure distribution over the longitudinal symmetry line. As discussed earlier, the pressure decreases along the stagnation line and therefore at each longitudinal section, the maximum pressure is far less than that on the longitudinal symmetry line. Using Swept Wing Theory, Morabito [13] was able to calculate the pressure reduction discussed above. He considered the velocity vector to be a combination of two components; one along the stagnation line and the other normal to it which is shown in Fig.4.

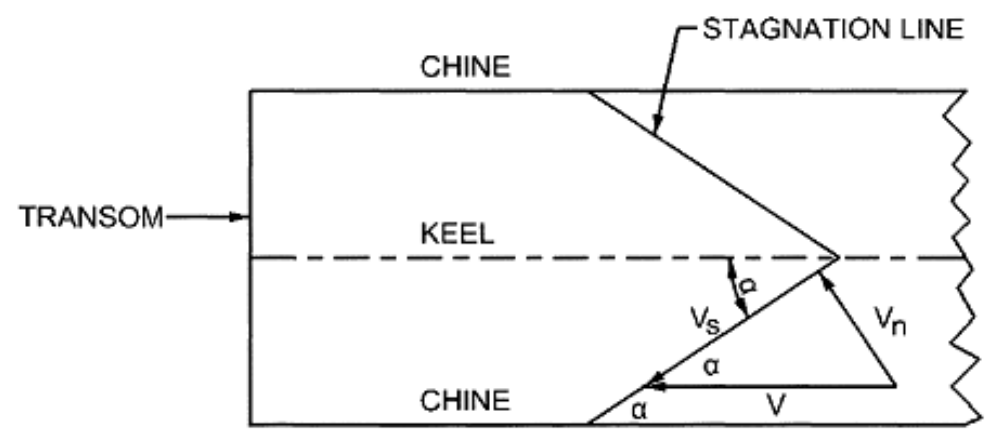

Fig.4: Components of the planing plane velocity vector [13].

The components of the velocity vector are presented as

$V_{n}=V \sin \alpha$

$V_{s}=V \cos \alpha$

$V_{n}$ in equations (12) and (13) is the velocity component normal to the stagnation line and $V_{s}$ is the component along the stagnation line. Using the normal component and the resulting pressure $P_{N}$, an empirical equation for the ratio of transverse pressure along the stagnation line $\left(P_{\gamma \text { stag }}\right)$ and $P_{N}$ is derived, which is given as Eq.(14). Multiplying this ratio by the maximum pressure gives the maximum pressure over the stagnation line at a desired longitudinal section. This is governed by Equation (15).

$\frac{P_{Y S T A G}}{P_{N}}=\left[1.02-0.25 Y^{1.4}\right] \frac{0.5-Y}{0.51-Y}$

$\frac{P_{M A X}}{q}=\frac{P_{Y S T A G}}{P_{N}} \operatorname{Sin}^{2} \alpha$

Apart from the stagnation pressure reduction at each longitudinal section, the pressure itself will experience a decrease which is governed according to the solution of Babyleff [16] as follows:

$P_{Y}=\left[1.02-0.05(\beta+5) Y^{1.4}\right] \frac{0.5-Y}{0.51-Y}$

where $P_{Y}$ is the ratio between the pressure at a transverse section with a dimensionless distance of $Y$ from the longitudinal symmetry line and the pressure at the longitudinal symmetry line of that same section. 


\subsection{Modeling method}

The modeling method that is discussed in the present paper is based on the equations introduced so far. The mathematical model uses two computational loops. The required inputs for modeling are the trim angle, dimensionless mean wetted length and dead-rise angle.

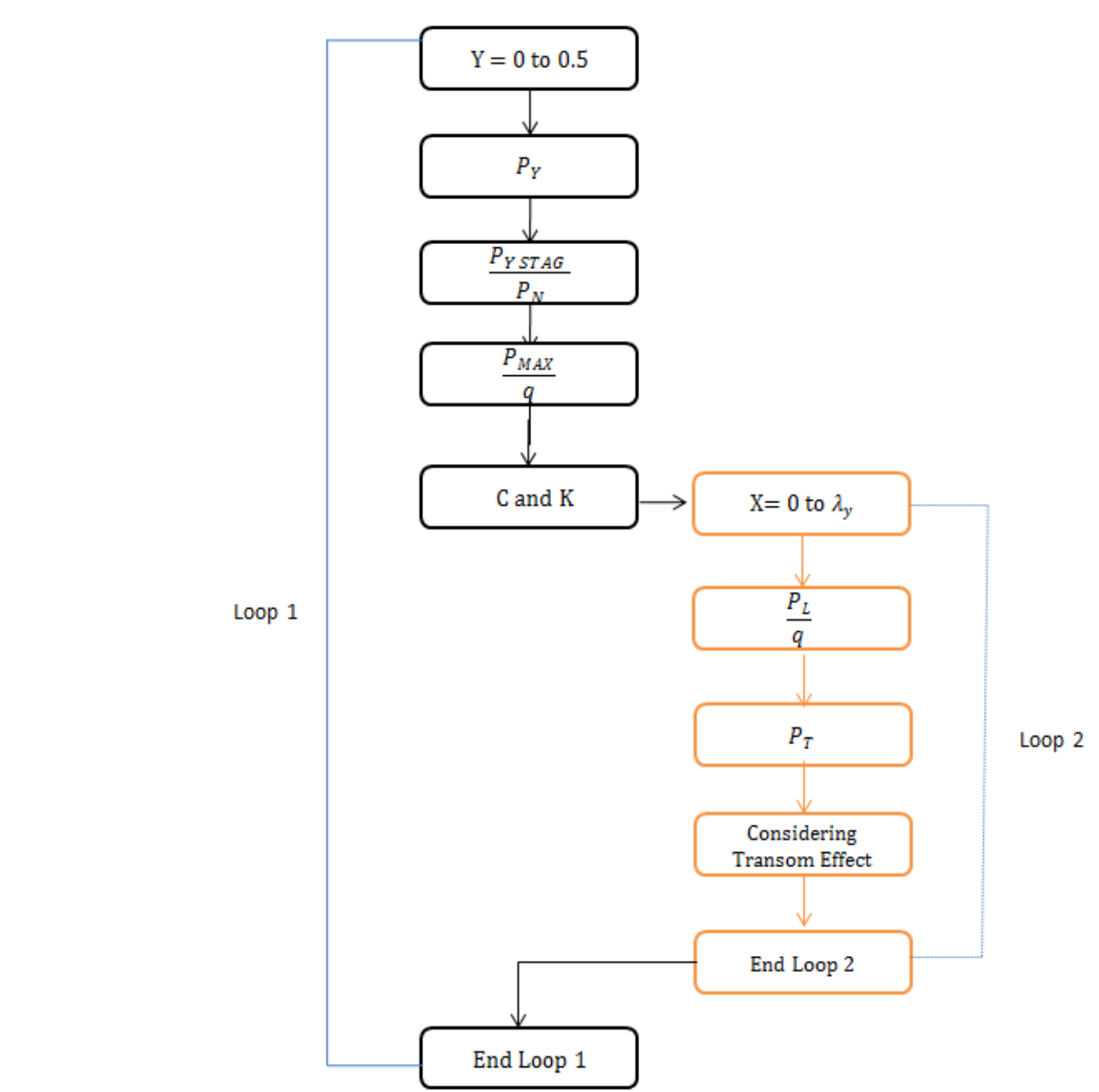

Fig.5: Computational algorithm for the present mathematical model used to calculated the pressure distribution at each longitudinal section.

First, the angle between the stagnation line and the longitudinal symmetry line (i.e. $\alpha$ ) is measured. The resulting matrix has rows in which each represents a longitudinal section (with fixed breadth) of a planing hull. Number of sections can be determined for the modeling from one section (without the first loop) to a desired level.

The value of $Y$ is chosen between 0 to 0.5 because of the fact that the planing hull has longitudinal symmetry along the keel line. In order to accurately calculate $C$, the transverse pressure reduction should be taken into consideration and therefore $C$ is calculated as follows:

$C=0.006 P_{Y} \tau^{\frac{1}{3}}$

\section{Validation}

Kapryan and Boyd [4] performed a set of experiments in order to evaluate the longitudinal dynamic pressure distribution in planing hulls. They executed these experiments in three longitudinal rows with dimensionless breadths of 
$0.025,0.25$ and 0.475 . In order to evaluate the accuracy of the present mathematical model, the obtained results are validated against the experimental results of Kapryan and Boyd [4] at the same three rows mentioned above.

Table 1: Kapryan and Boyd [4] experimental setup for 26 different cases.

\begin{tabular}{|c|c|c|c|c|c|c|c|}
\hline \multicolumn{4}{|l|}{ Case NO } & \multicolumn{4}{|l|}{ Case NO } \\
\hline 1 & 0 & 4 & 5.12 & 14 & 20 & 6 & 5.11 \\
\hline 2 & 0 & 6 & 5 & 15 & 20 & 9 & 0.95 \\
\hline 3 & 0 & 9 & 2.74 & 16 & 20 & 9 & 2.5 \\
\hline 4 & 0 & 9 & 4.97 & 17 & 20 & 9 & 4.97 \\
\hline 5 & 0 & 12 & 2.61 & 18 & 20 & 12 & 4.98 \\
\hline 6 & 0 & 18 & 1 & 19 & 20 & 18 & 2.53 \\
\hline 7 & 0 & 24 & 1.06 & 20 & 20 & 24 & 0.97 \\
\hline 8 & 0 & 30 & 1.07 & 21 & 20 & 30 & 1.06 \\
\hline 9 & 20 & 4 & 2.25 & 22 & 40 & 9 & 4.7 \\
\hline 10 & 20 & 4 & 4.2 & 23 & 40 & 12 & 4.88 \\
\hline 11 & 20 & 6 & 1.74 & 24 & 40 & 18 & 2.5 \\
\hline 12 & 20 & 6 & 2.36 & 25 & 40 & 24 & 2.46 \\
\hline 13 & 20 & 6 & 2.94 & 26 & 40 & 30 & 1.02 \\
\hline
\end{tabular}

The experimental setups of Kapryan and Boyd [4] are presented in Table 1. Results of the validation tests are shown in Figs.6 to 11 for six different cases. In each figure, lines refer to the results of the present numerical method and the scattered points refer to the experimental results of [4]. Also, the distance behind the stagnation line is presented using dashed lines.

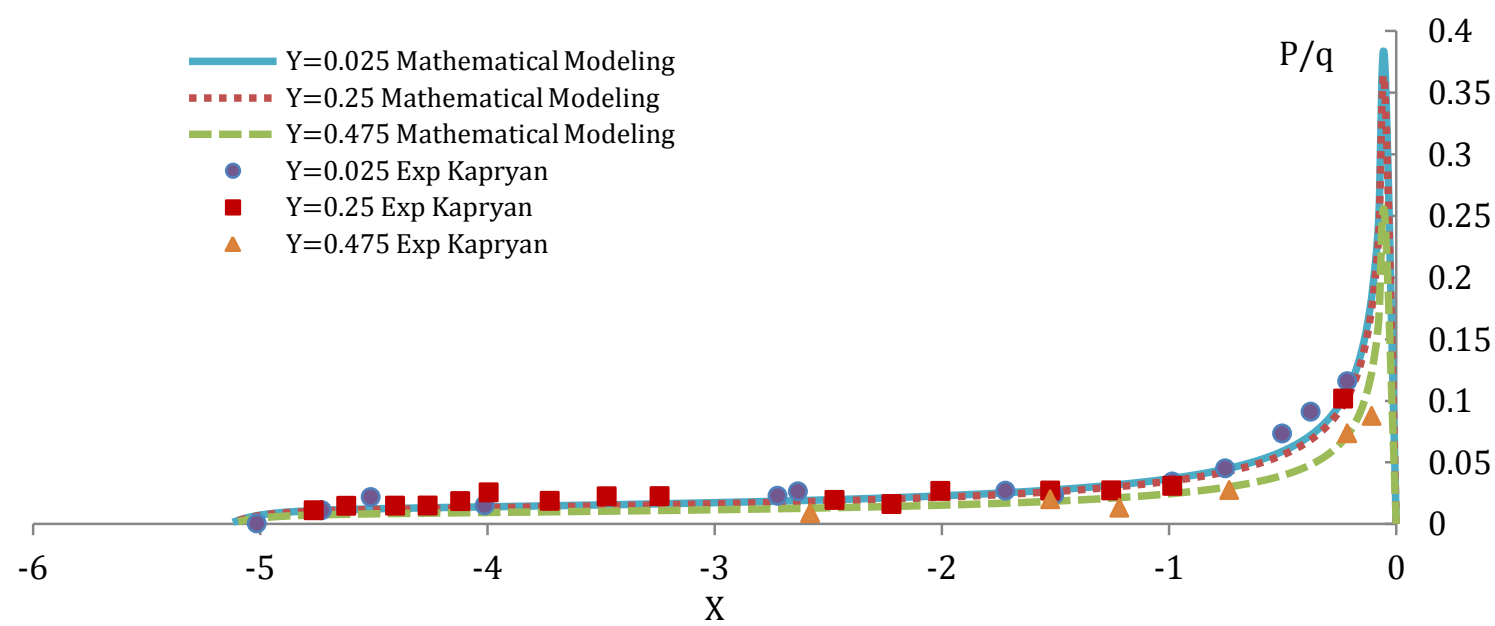

Fig.6. Comparison of the numerical results with the experimental results of [4] for Case 1.
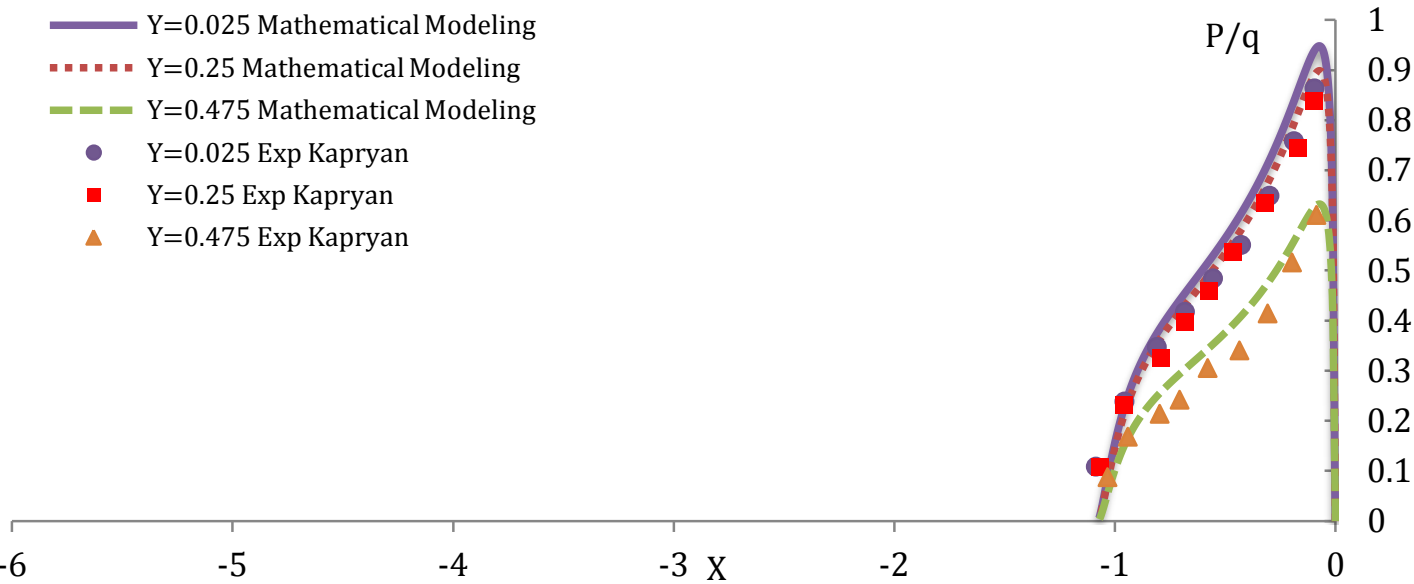

Fig.7. Comparison of the numerical results with the experimental results of [4] for Case 8 . 


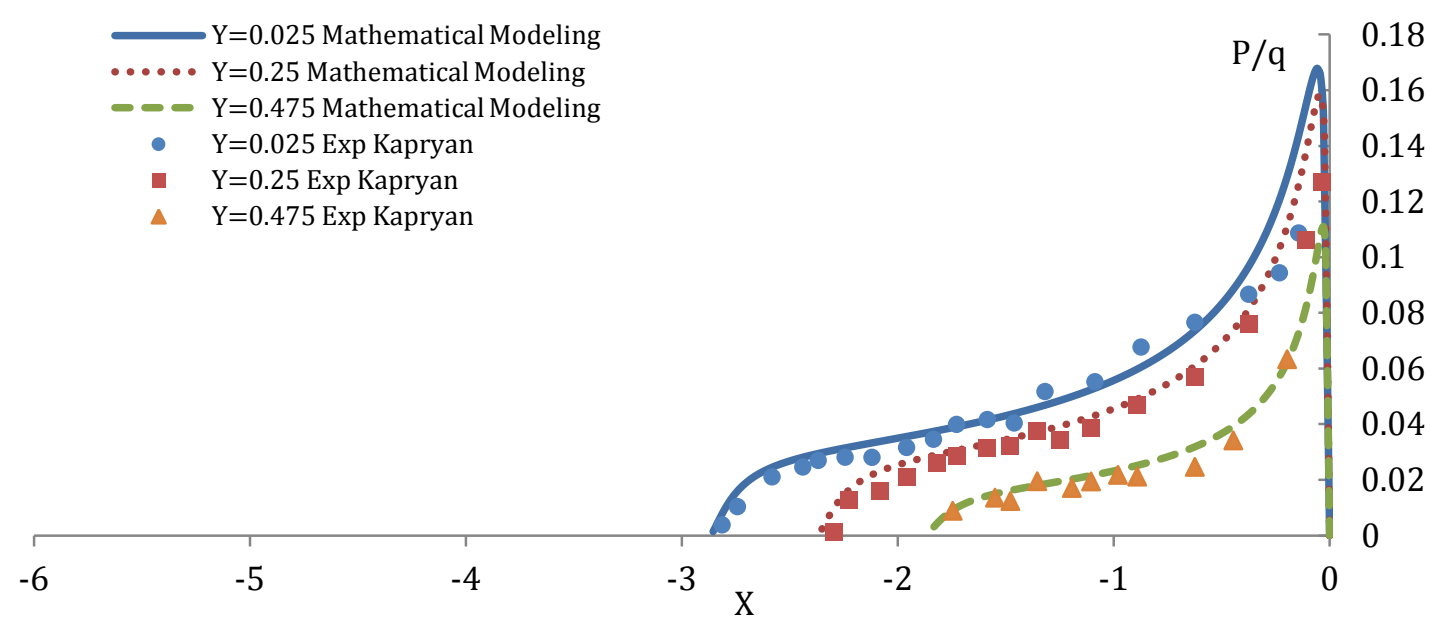

Fig.8. Comparison of the numerical results with the experimental results of [4] for Case 12.

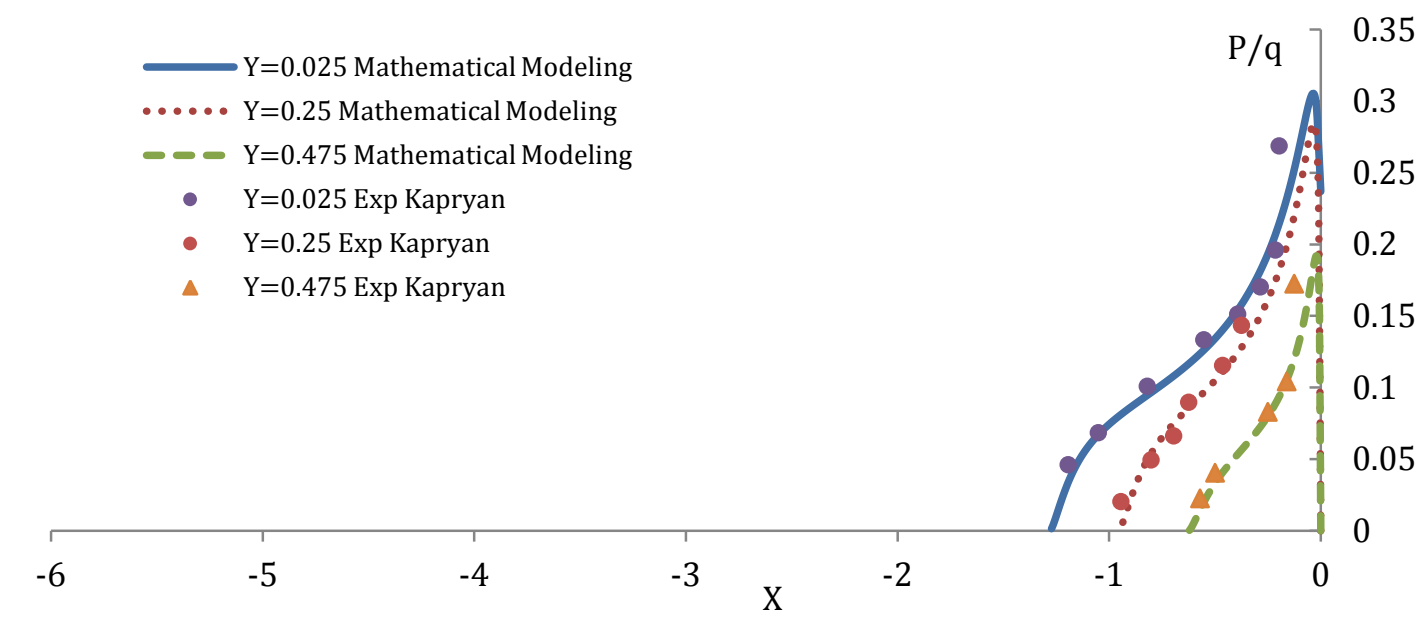

Fig.9. Comparison of the numerical results with the experimental results of [4] for Case 15.

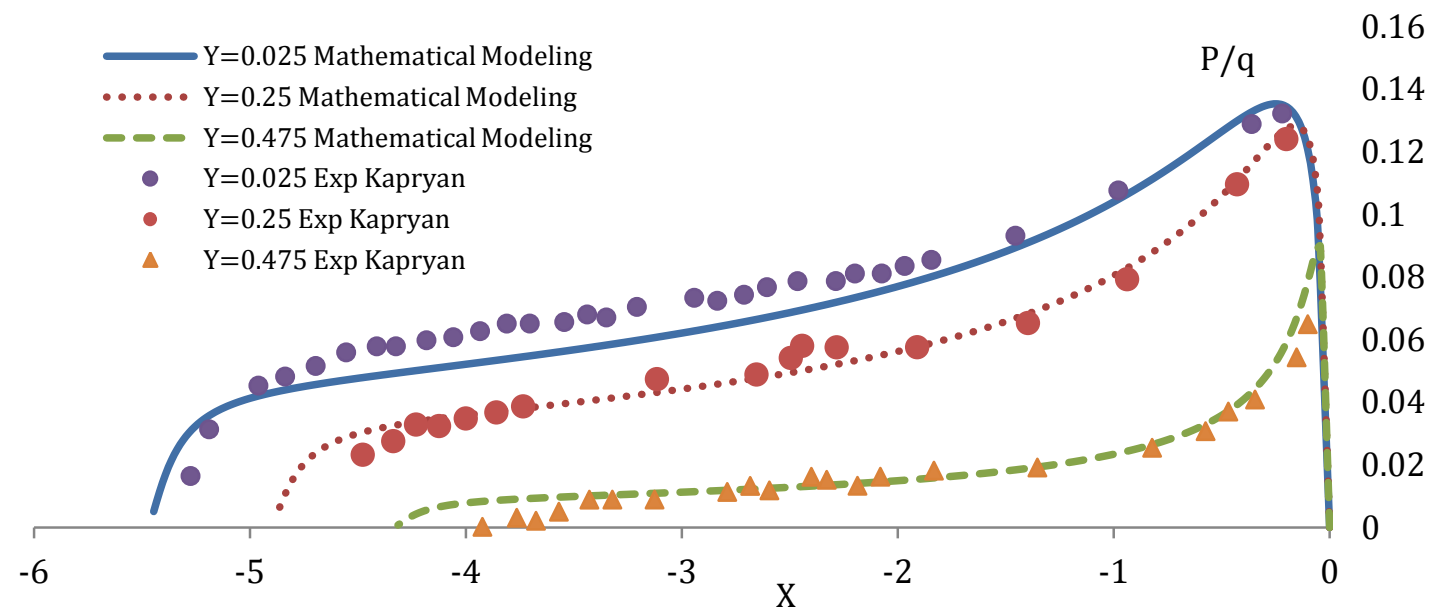

Fig.10. Comparison of the numerical results with the experimental results of [4] for Case 23. 


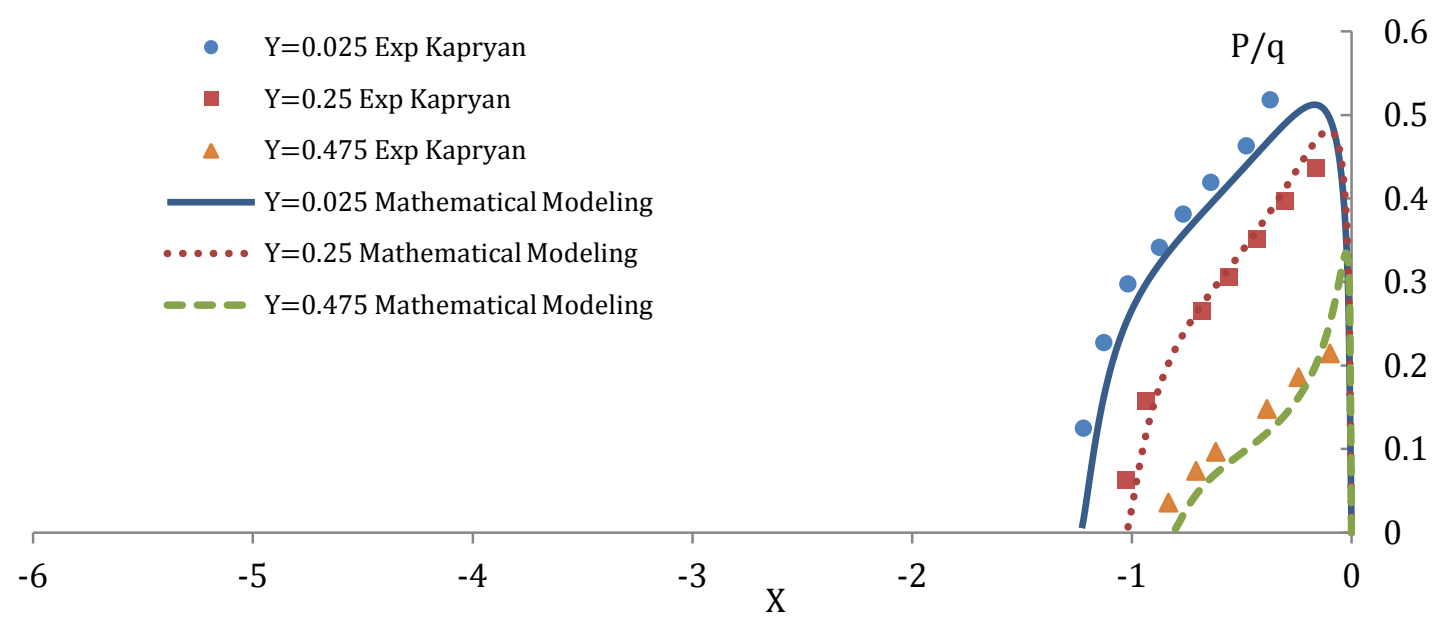

Fig.11. Comparison of the numerical results with the experimental results of [4] for Case 26.

\section{Results}

The present mathematical model is used to analyze three different problems:

1. The effect of trim angle on the longitudinal dynamic pressure distribution

2. The effect of dead-rise angle on the longitudinal dynamic pressure distribution

3. The effect of wetted length on the longitudinal dynamic pressure distribution

\subsection{Effect of the trim angle}

In order to study the effect of the trim angle, the longitudinal distribution of the pressure over the longitudinal symmetry line of a planing hull with dead-rise angles of 5, 10, 20, 30 and 45 degrees at trim angles of 2, 4, 6 and 8 degrees are evaluated. The mean wetted length is kept constant for all cases. The increase in trim angle causes the angle between the stagnation line and the longitudinal symmetry line to increase. Also, it will result in an overall increase in pressure distribution in planing hulls. Figures 12 to 16 depict the numerical results using the present mathematical model showing the effect of the trim angle on the pressure distribution.

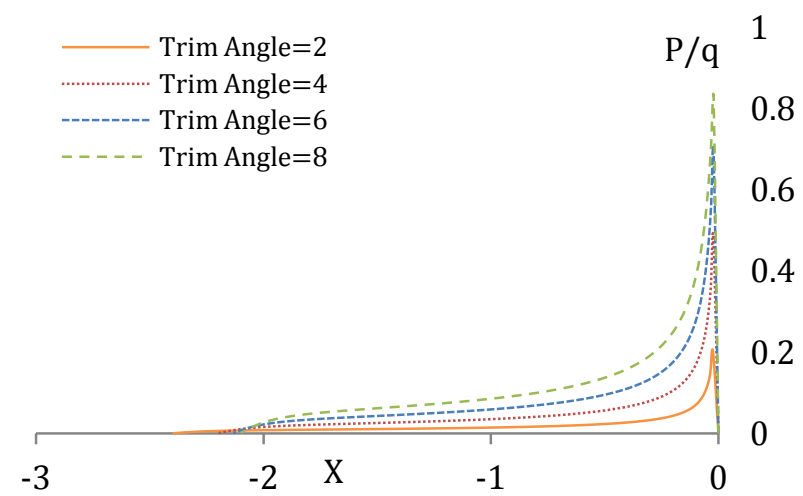

Fig.12. The effect of the trim angle on the longitudinal distribution of the dynamic pressure in planing hulls at $\beta=5$. 


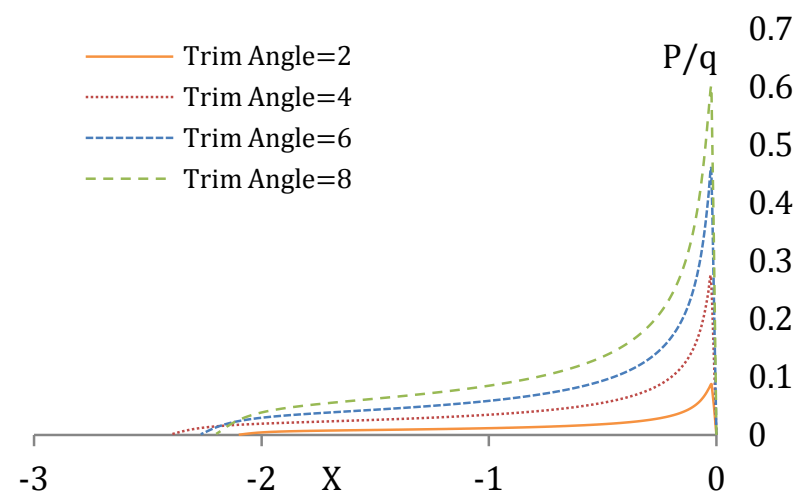

Fig.13. The effect of the trim angle on the longitudinal distribution of the dynamic pressure in planing hulls at $\beta=10$.

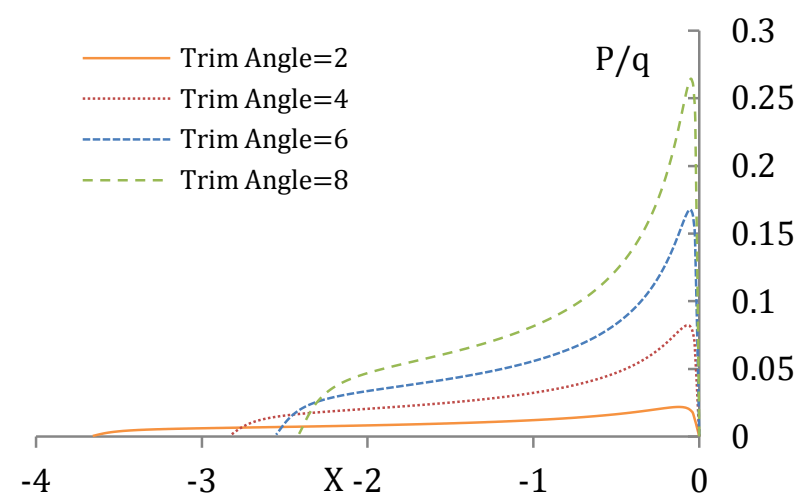

Fig.14. The effect of the trim angle on the longitudinal distribution of the dynamic pressure in planing hulls at $\beta=20$.

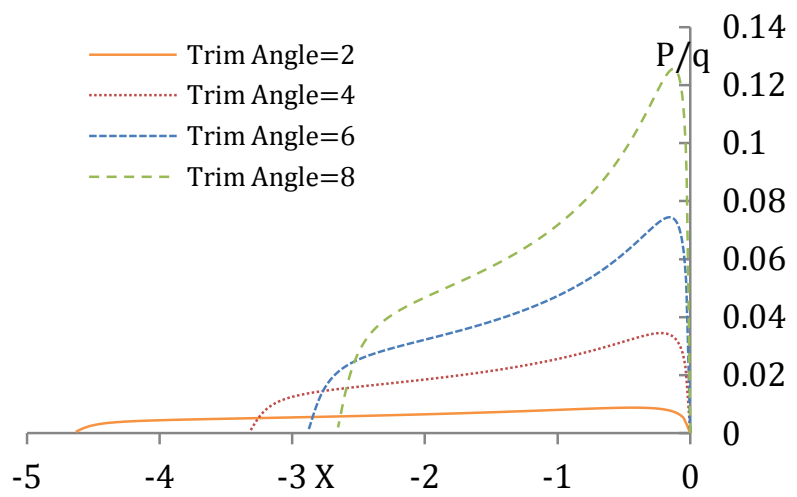

Fig.15. The effect of the trim angle on the longitudinal distribution of the dynamic pressure in planing hulls at $\beta=30$.

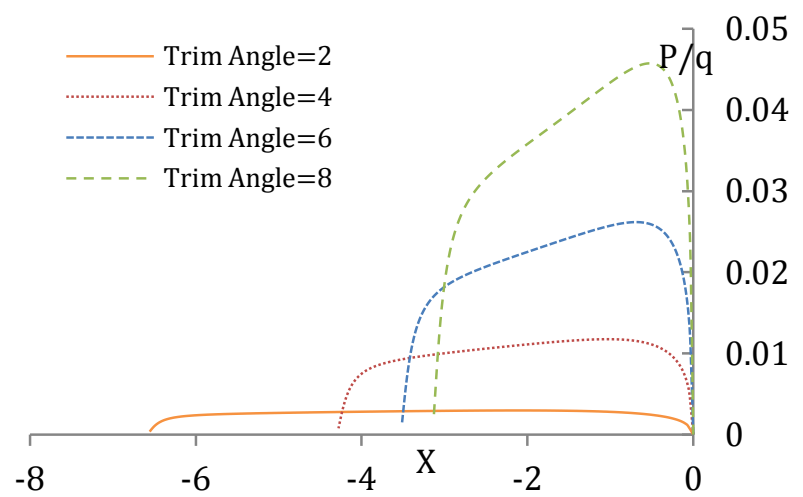

Fig.16. The effect of the trim angle on the longitudinal distribution of the dynamic pressure in planing hulls at $\beta=45$. 
Based on Figs. 12 through 16, it is clear that an increase in trim angle at a constant dead-rise angle and a constant wetted length, will result in an increase in the pressure distribution, while the distance between the transom stern and the stagnation line will decrease.

\subsection{Effect of the dead-rise angle}

In order to study the effect of the dead-rise angle, the longitudinal distribution of the pressure over the symmetry line of a planing hull at a constant trim angle is evaluated. The results for different dead-rise angles at constant trim angles of 2 , 4, 6 and 8 degrees are presented in Figs. 17 through 20.

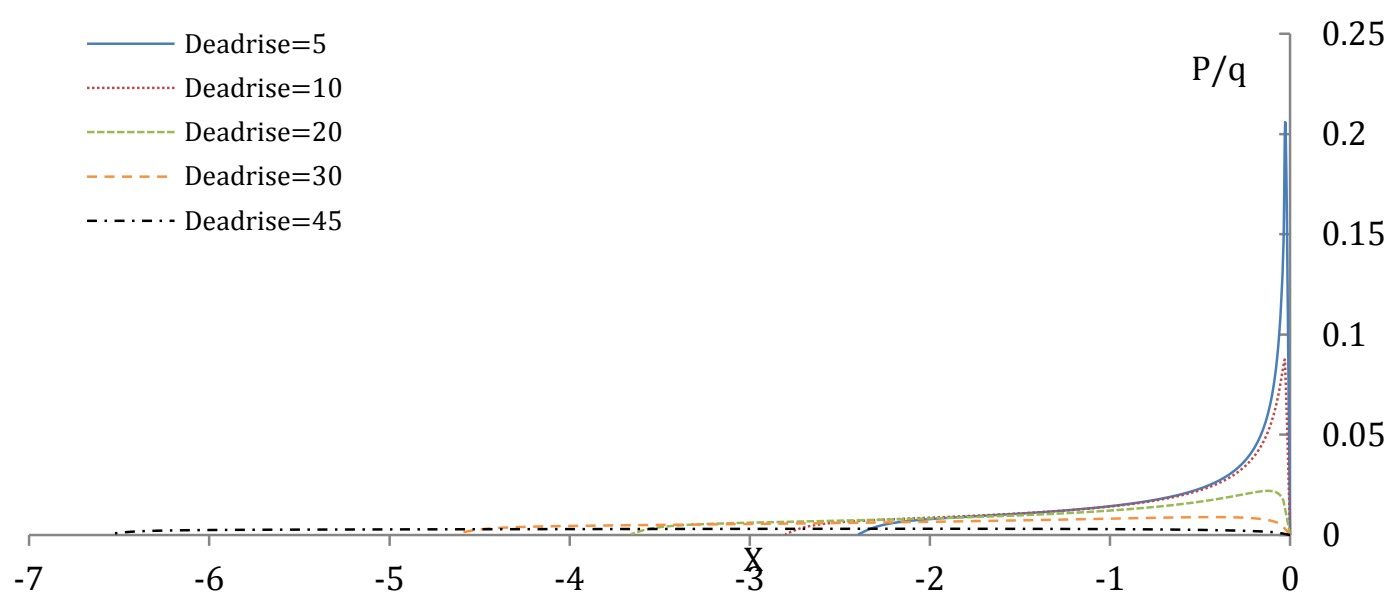

Fig.17. The effect of the dead-rise angle for $\tau=2$.

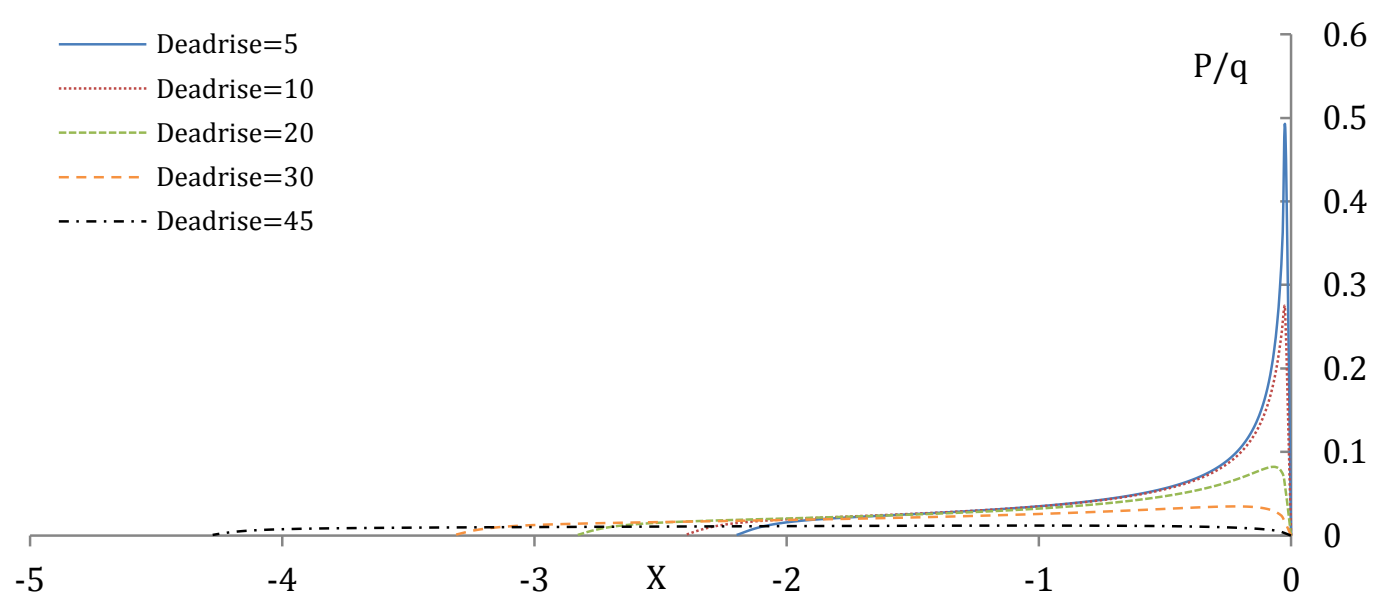

Fig.18. The effect of the dead-rise angle for $\tau=4$.

As it is shown on Fig. 17 to 20, increasing the dead-rise angle at a constant trim angle and wetted length will cause the maximum pressure at each longitudinal section to decrease while it does not have a major effect on the pressure distribution.

\subsection{Effect of the wetted length}

The effect of the wetted length is experienced in the stern regions of the planing hull and is not seen in the front regions. As a result, the effect of the wetted length is studied through different test cases with trim angles of 4 and 6 degrees and dead-rise angles of 10 and 20 degrees. The results are presented in Fig. 21 and 22 in terms of longitudinal pressure distribution over the longitudinal symmetry line. 


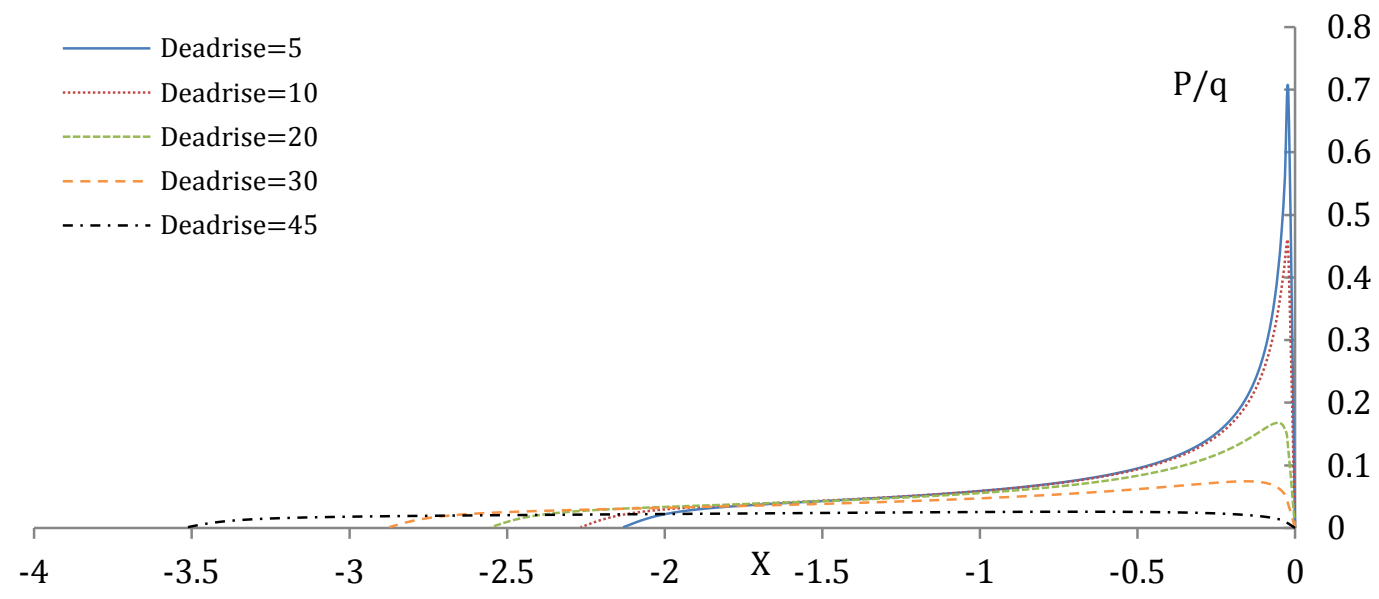

Fig.19. The effect of the dead-rise angle for $\tau=6$.

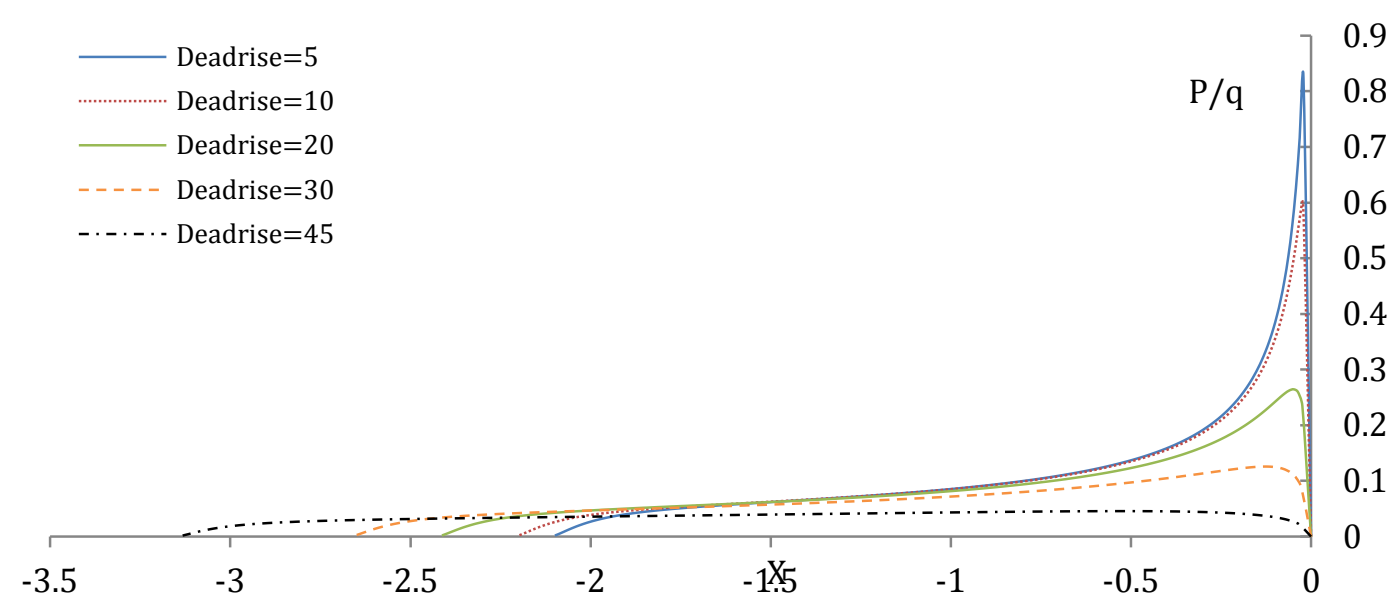

Fig.20. The effect of the dead-rise angle for $\tau=8$.

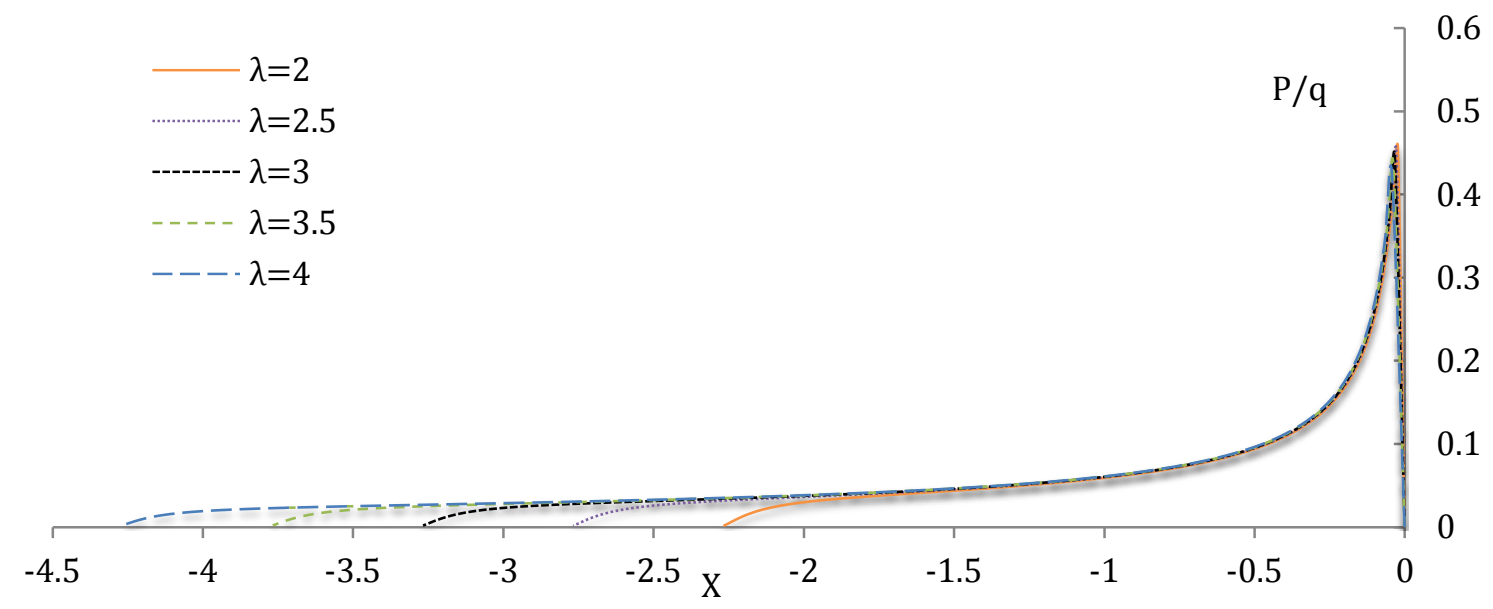

Fig.21. The effect of the wetted length on the longitudinal pressure distribution at $\tau=6$ and $\beta=10$. 


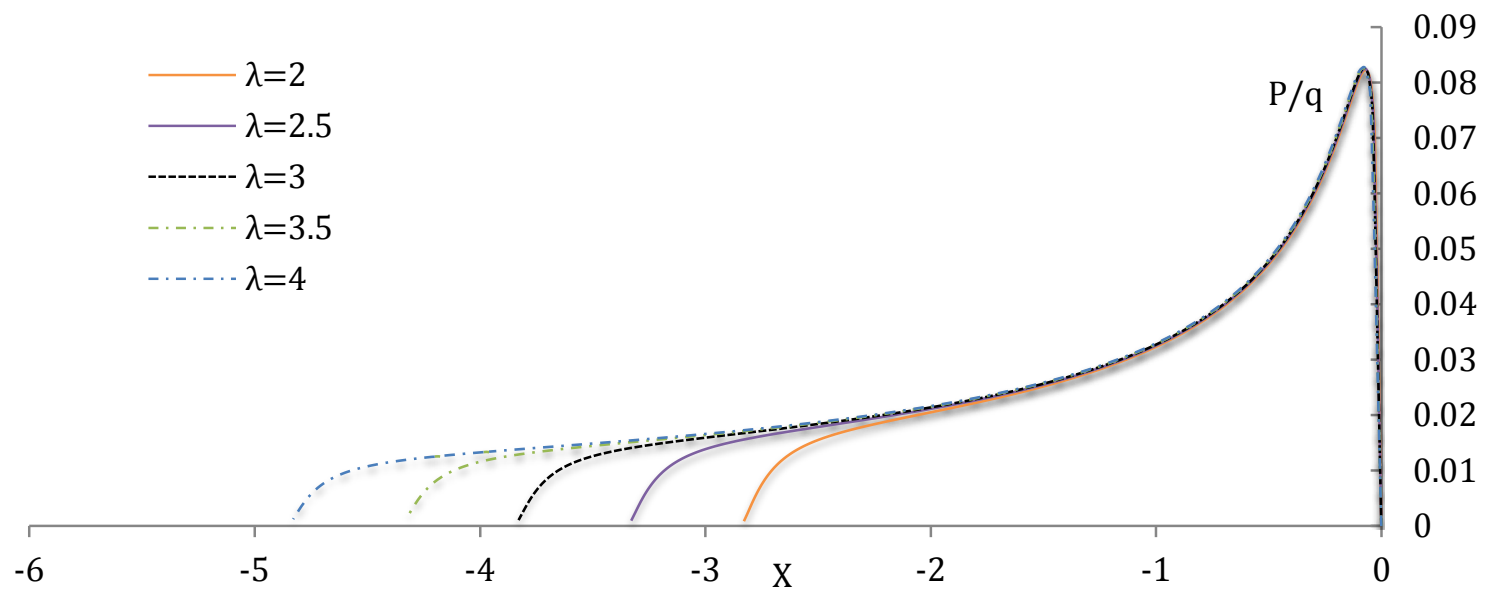

Fig.22. The effect of the wetted length on the longitudinal pressure distribution at $\tau=4$ and $\beta=20$.

It is obvious that the wetted length will only affect the pressure distribution at the stern regions of the planing plane and has no effect at the front sections.

\section{Conclusion}

In the present paper, a mathematical model based on empirical equations is introduced. This method proved to be advantageous in terms of low cost of computation and time efficiency. As a result of this, the effects of trim and deadrise angles and the mean wetted length are studied simply and effectively comparing to the expensive and time consuming experimental approaches. Comparison between the obtained results from the present mathematical model and the experimental results of Kapryan and Boyd [4] vouches for the efficiency and favorable accuracy of the proposed method. In this article, the effects of trim and dead-rise angles and the mean wetted length on the longitudinal pressure distribution are studied. Results show that the increase of trim angle will lead to an increase in the distributed pressure while decreasing dead-rise angle results in the reduction of the maximum pressure in planing planes. Additionally, changes in the mean wetted length will only affect the pressure distribution in the stern regions of the planing plane and will not affect the front regions.

While many efforts have been directed toward the application of empirical equations for the pressure and force modeling of planing hulls, research studies on the 3-dimensional modeling of the pressure distribution over the monoand twin-hull planing boats, calculation of lift forces acting on this type of boats and the pressure modeling of the stepped planing hulls are required to be considered and analyzed.

\section{References}

[1] Wagner, H. "Phenomena Associated with Impacts and Sliding on liquid surfaces." NACA Translation, 1932.

[2] Sottorf, W. "Experiments with Planing Surfaces", NACA transactions, 1934.

[3] Smiley, R.F. "A Study of Water Pressure Distribution during Landing with Special Refrence to a Prismatic Model Having a heavy Loading and a 30-Degree Angle of Deadrise", NACA Translation, 1950.

[4] Kapryan, W.J. and Boyd .G.M. "Hydrodynamic Pressure Distribution Obtained During a Planing Investigation of Five Related Prismatic Surfaces.", NACA Technical Note, 1955.

[5] Savitsky, Daniel "Hydrodynamic Design of Planing Hulls.", Marine Technology, Volume 1, 1964.

[6] Allen. R.G. and Jones, R.R. "A Simplified Method for Determining Structrul Fdesign-Limit Pressures on High Performance Marine Vehicles." AIAA/SNAME Advanced Marine Vehicle Conference. San Diego, California, 1978..

[7] Payne, R.P. "The Dynamic Force on a Two-Dimenssional Planing Plate of Arbitary Camber.", Journal of Ocean Engineering, Volume 9, 1982.

[8] Battistin, D. and Iafrrati"A Numerical Model for Hydrodynamoc of planing Surfaces.“, Proc. 7th Int. Conf. Fast Sea Transportation FAST2003, , 2003.

[9] Akimoto, H., Iida, K. and Kubo, S. "Numerical Simulation of the Flow around a Planing Wedged Cylinder by a Particale Methode.", Journal of Naval Architects of Japan, Vol.176, 2004.

[10] Kihara, H. "A Computing Methode for the Flow Analysis around a Prismatic Planing-Hull." 2nd International Conference on High Performance Marine Vehicles, Australia, 8-10 November 2006.

[11] Savitsky, D., Delorme, M.F. and Datla, R. "Inclusion of Whisker Spray in Performance Prediction Method for High Speed Planing Hulls." SNAME marine Technology, Vol 44, 2007.

[12] Pierson, J.D. and Leshnover, S. "A Study of the Flow, Pressure and Loads Pertaining to Prismatic Vee-Planing Surfaces." Report SIT DL 50 382 Davison Laboratory, 1950. 
[13] Morabito, M.G. "On The Spray and Bottom Pressures of Planing Surfaces." PhD Thesis.Under Supervision of Datla, R. and Savitsky, D. Civil Environmental and Ocean Engineering Department. Stevens Institute of Technology, 2010.

[14] Smiley, R.F. 1951. "An Experimental Study of the Water-Pressure Distributions During Landing and Planing of a Heavily Loaded Rectangular Flat-Plate Model." NACA Technical Note NO. 2453, 1951.

[15] Babyleff. 1881. Journal of the Russian Physico-Chemical Society, xiii, 1881. 